\title{
Cascade testing in familial hypercholesterolaemia: how should family members be contacted?
}

\author{
Ainsley J Newson* ${ }^{*, 1}$ and Steve E Humphries ${ }^{2,3}$ \\ ${ }^{1}$ Medical Ethics Unit, Imperial College London, London, UK; ${ }^{2}$ London IDEAS Genetics Knowledge Park, London, UK; \\ ${ }^{3}$ Centre for Cardiovascular Genetics, Royal Free and University College London Medical School, London, UK
}

Cascade testing or screening provides an important mechanism for identifying people at risk of a genetic condition. For some autosomal dominant conditions, such as familial hpercholesterolaemia (FH), identifying relatives allows for significant health-affecting interventions to be administered, which can extend a person's life expectancy significantly. However, cascade screening is not without ethical implications. In this paper, we examine one ethically contentious aspect of cascade screening programmes, namely the alternative methods by which relatives of a proband can be contacted. Should the proband be invited to contact his or her family members, or should the screening programme contact family members directly? We argue that direct contact is an ethically justifiable method of contact tracing in cascade screening for FH. Not only has this method already been utilised without adverse effects, an examination of the ethical arguments against it shows these are unsubstantiated. We describe several criteria that, if met, will allow an appropriate balance to be struck between maximising the efficiency of family tracing and respecting the interests of probands and their relatives.

European Journal of Human Genetics (2005) 13, 401-408. doi:10.1038/sj.ejhg.5201360

Published online 19 January 2005

Keywords: cascade genetic screening; cascade testing; confidentiality; autonomy; genetics; ethics; guidelines; familial hypercholesterolaemia

\section{Introduction}

Familial hypercholesterolaemia (FH) cascade screening

An autosomal dominant condition, $\mathrm{FH}$ is primarily caused by mutations in the low-density lipoprotein receptor (LDLR) gene. ${ }^{1,2}$ If left untreated, FH leads to substantially elevated serum cholesterol concentrations and a more than $50 \%$ risk of coronary heart disease (CHD) by age 50 in men and at least $30 \%$ in women by age $60 .{ }^{3}$ With an estimated prevalence of 1 in 500, approximately 110000 people in the United Kingdom are thought to have $\mathrm{FH}$, although at least $75 \%$ of this group remain undiagnosed. ${ }^{4}$ Preventative

${ }^{*}$ Correspondence: Dr AJ Newson, Medical Ethics Unit, Imperial College London, 3rd Floor, Reynolds Building, St Dunstan's Road, London W6 8RP, UK. Tel: + 44207594 0807; Fax: + 44207594 0854;

E-mail: a.newson@imperial.ac.uk

Received 23 June 2004; revised 7 October 2004; accepted 12 November 2004 treatment with HMG-CoA reductase inhibitors (statins), in combination with a healthy lifestyle, is effective in delaying or preventing the onset of CHD., 6 Effective primary prevention, however, requires early diagnosis.

Diagnosis of FH is based on the presence of elevated plasma total and low-density lipoprotein cholesterol, plus clinically detected stigmata and a family history of either early CHD or elevated lipid levels. An unequivocal diagnosis can also be made by the carriage of a pathogenic LDLR mutation, identified by a DNA-based test. ${ }^{7}$ The utility of DNA testing remains limited, however, as a mutation is currently identified in only $30-60 \%$ of clinically diagnosed cases. ${ }^{8}$

Despite these potential difficulties, a recent modelling exercise and review have suggested that cascade testing based on lipid or genetic testing in the relatives of known FH probands is cost effective in terms of life-years gained. ${ }^{8,9}$ Further, a Netherlands-based DNA testing 
programme has been running for more than 5 years, ${ }^{10}$ with good recruitment rates and reported patient satisfaction. ${ }^{11}$

Policy support in light of this clinical effectiveness was demonstrated by the United Kingdom Government in its 2003 White Paper on Genetics, where a commitment to pilot cascade testing for $\mathrm{FH}$ was made. ${ }^{12}$ The 2-year programme will identify new cases from the relatives of $\mathrm{FH}$ patients already attending lipid clinics, with the aim of finding two new FH patients for every known proband. The pilot will also address whether cascade testing (based on measurement of plasma lipid levels) is acceptable, feasible and cost effective within the current organisation of the NHS and contemporary social structures. It will also consider whether different approaches to cascade testing are warranted in different social groups, and will delineate the education and training requirements for national implementation.

It is important to recognise that undertaking cascade screening for a genetic condition by measuring a plasma trait, as opposed to using a DNA test, does not mean that concerns typically associated with genetic testing are avoided. A person's test result will still have implications for his or her family members, and may affect life planning, employment or one's ability to obtain life insurance. ${ }^{13}$ However, existing cascade screening programmes for $\mathrm{FH}$ have shown little, if any, long-term detrimental effects upon participants' quality of life. ${ }^{11,14,15}$

\section{Relative contact in cascade testing}

Cascade testing provides one method for identifying relatives at risk of a particular heritable condition. Once an affected proband is recognised, his or her first (or second) degree relatives are systematically identified, contacted and offered information, after which they can decide whether to undergo testing. For FH, targeted cascade screening will provide a greater rate of case identification than general population screening. ${ }^{8,9}$

The success of cascade screening programs is dependent on a high pickup rate from the tracing of a proband's first and second-degree family members ('contact tracing'), both of which depend on information being reported by the proband. ${ }^{16}$ Broadly, two alternative methods can be used to establish contact with a proband's relatives. These are family contact, which involves providing information and clinic contact details to the proband, who will then pass this on to his or her relatives (also called 'proband initiated contact ${ }^{\prime 17}$ ); and direct contact, where probands are invited to provide the clinic with relatives' names and contact details, so the clinic can contact them directly.

Both methods of contact tracing raise ethical and legal issues. In particular, there is an ethical tension between maximising the utility of cascade screening and respecting the interests of probands and their relatives. Clinicians have an obligation to protect the confidentiality of the proband, but this must be balanced with the central purpose of cascade testing; namely to promote autonomous decision-making by relatives about their genetic risk. This purpose would be hampered by inefficient or ineffective family communication processes. It is also important to recognise that the legal applicability of the two contact strategies may vary from country to country depending on legal rules and a particular country's system of health care. For example, direct contact would not be possible in Norway, where privacy laws prevent physicians from contacting relatives who are not their patients. ${ }^{18}$

Family contact represents standard practice in clinical genetics and some family linkage studies. If this method is used, a proband's relatives may be less at risk of psychological harm through unsolicited contact. Their confidentiality is also protected. However, response rates using this method are likely to be lower. Given normal family contexts, information passed on to relatives from probands may have less impact than would an approach from a health professional. Or, probands may never 'get around' to contacting relatives. Direct contact tracing is less likely to encounter such problems and so more relatives are likely to present for screening.

Below, we further explore the ethical tension between these two methods of contact. We argue that direct contact is ethically justifiable in the case of FH cascade screening, provided certain provisions are adhered to. Although the legal implications of unsolicited contact need to be borne in mind, ${ }^{19}$ we believe the risk that this will cause shock and anxiety can be managed, and propose criteria to achieve this.

\section{Previous cascade screening programmes}

We performed a systematic literature search to identify published studies involving cascade genetic screening and identify those that explicitly described the method of contact tracing employed and its psychosocial outcomes (see Table 1). Both family and direct contact have been employed, and discussion of these studies is divided into cascade screening for $\mathrm{FH}$, and cascade screening for other genetic conditions.

\section{FH cascade screening}

In the UK, FH cascade screening has been carried out on a small scale in two studies using direct contact tracing. ${ }^{15,20}$ In the first, ${ }^{20}$ each proband provided a family history, including contact details for first-degree relatives. Relatives were then sent a personalised standard letter explaining their at-risk status, the importance of this information and the options available. This approach was also used in the 'GRAFT' study; ${ }^{15}$ however, no data were available on relatives' views about direct contact.

A cascade screening study has been carried out in The Netherlands, although a DNA-based test was used. ${ }^{10,21}$ Direct contact tracing was employed, with probands 
Table 1 Summary of empirical investigations into cascade screening

\begin{tabular}{|c|c|c|c|c|}
\hline Country & Study & Disease & Method & Outcome of contact method? \\
\hline UK & Bhatnagar et al (2000) & $\mathrm{FH}$ & Direct contact & Not specifically addressed \\
\hline Holland & van Maarle et al (2001) & $\mathrm{FH}$ & Direct contact & $\begin{array}{l}\text { Proband informed relatives before } \\
\text { direct contact; } 90 \% \text { satisfaction }\end{array}$ \\
\hline UK & Marteau et al (2004) & $\mathrm{FH}$ & Direct contact & Not specifically addressed \\
\hline Norway & Tonstad et al (1995) & $\mathrm{FH}$ & Family contact & Participants favoured direct contact \\
\hline Denmark & Wilcke et al (1999) and (2000) & $\alpha-1 \mathrm{AT}$ & Direct contact & $\begin{array}{l}\text { Direct contact acceptable so long } \\
\text { as probands could contact relatives } \\
\text { first }\end{array}$ \\
\hline UK & $\begin{array}{l}\text { Wright et al (2002); } \\
\text { Kerzin-Storrar et al (2002) }\end{array}$ & DMD & $\begin{array}{l}\text { Family contact } \\
\text { or direct contact }\end{array}$ & $\begin{array}{l}\text { Probands ( } 78 \%) \text { and relatives } \\
(90 \%) \text { accepted clinic passing on } \\
\text { information }\end{array}$ \\
\hline UK & $\begin{array}{l}\text { Super et al (1994); } \\
\text { Roberts et al (2003) }\end{array}$ & $\mathrm{CF}$ & Family contact. & $\begin{array}{l}\text { Not specifically addressed but } \\
\text { good uptake }\end{array}$ \\
\hline
\end{tabular}

consenting in writing to have their test results released to those first and second-degree relatives for whom contact information had been provided. The proband was also asked to inform his or her relatives about $\mathrm{FH}$ before they were approached by the clinical team. The psychological implications of the whole screening programme were investigated by interviewing over 600 relatives who had participated. ${ }^{21}$ Overall, $90 \%$ were satisfied with the method by which they were approached. Additionally, $88 \%$ disagreed with the statement that it was improper to be approached without first being asked by a relative.

In Norway, where direct contact is not possible under current laws, Tonstad et al ${ }^{18,22}$ asked probands to inform other family members about their diagnosis and need for screening (family contact tracing). However, the attitudes of probands towards $\mathrm{FH}$ screening supported direct contact. Of the $77 \%$ of relatives who were interested in testing, $74 \%$ wished to be informed directly by the proband's physician, rather than by the proband.

\section{Cascade screening for other conditions}

Cascade screening has also been undertaken for other conditions with a different mode of inheritance to $\mathrm{FH}$. Although it has been reported that cascade testing is not an efficient method of population screening for autosomal recessive disorders, ${ }^{23}$ it is nonetheless relevant to examine these studies to discern participant's attitudes towards the method of family tracing used.

In Denmark, a cascade screening programme has been carried out for the recessive condition $\alpha-1$ Anti-trypsin deficiency. ${ }^{24,25}$ Direct contact was employed: after consenting to participate, the proband was asked to provide the names and contact details of relatives. The register wrote a letter to relatives summarising the condition and their risk. ${ }^{25}$ An examination of attitudes towards the method of relative contact indicated that $75 \%$ of probands would not rule out an unsolicited approach if it was difficult for the index case to inform relatives. ${ }^{25}$ However, respondents felt that the proband should first be given the opportunity to inform relatives. Attitudes to approaching relatives also varied with factors such as the relative's age, whether they have children and their emotional relationship with the proband.

In assessing a cascade screening programme for the X-linked condition Duchenne Muscular Dystropy, ${ }^{26,27}$ Wright et $a l^{26}$ found that $98 \%$ of probands were happy to pass information on to relatives, and $78 \%$ thought it acceptable for risk information to be provided by the genetics service. If the proband was unable to discuss the condition with relatives but was happy for contact to be made, this was initiated via the relative's GP, without disclosing the nature of the condition. ${ }^{26}$ In 51 interviews with at-risk relatives, none stated it was unacceptable for them to be proactively informed about their risk. ${ }^{27}$ Percentage acceptance of various methods of contact was very similar: $94 \%$ accepted being told by a family member, while $90 \%$ accepted being told by the genetics service.

A cystic fibrosis cascade screening program has been run in Manchester for over 10 years, using family contact. ${ }^{20,28}$ After a family tree was drawn up in conjunction with the clinical team, probands invited participation from their relatives through passing on a booklet describing $\mathrm{CF}$ and the opportunity for testing. Cascade screening has been generally well accepted, with uptake greater than expected: on average, 20 additional tests were performed per family.

\section{Direct contact: ethical issues}

The clinical investigation team, probands, relatives and broader society are likely to have varying interests and values with respect to cascade screening, which could give rise to tensions. For example, the investigation team's motivation to promote health care within a wider group may conflict with the interests of relatives in maintaining privacy over their personal information. The ethical issues 
raised by direct contact tracing can be grouped into six main classes.

\section{Psychological harm to relatives}

Arguably the greatest concern with direct contact in cascade testing is the potential for probands' relatives to experience psychological harm. A relative who receives an unexpected letter containing serious medical information from a previously unknown clinical team could experience feelings of shock, anger and anxiety. ${ }^{25}$ In contacting relatives directly, an important checkpoint is removed: probands, who will tend to have good knowledge of the personality traits and dynamics present within their families.

However, the actual risk of psychological harm through unsolicited contact may not be large. In a small study examining screening for several conditions, no relatives who had been approached directly experienced feelings of anger or annoyance. ${ }^{26}$ Indeed, probands' relatives were virtually unanimous that the genetic risk knowledge was beneficial. Although half of the relatives did experience apprehension or anxiety, most also reported relief. Such initial concerns about health are a natural reaction to this information, and these are rarely long-term in duration.

This suggests that if the proband is first provided with general information to pass on to relatives, the potential for shock through unsolicited contact could be minimised. Probands could also be encouraged to informally discuss screening with relatives and alert the clinical team if there are any contextual family features that would warn against employing direct contact.

\section{The right 'not to know'}

Related to concerns with psychological harm is the concern that directly contacting probands' relatives will breach their right 'not to know' their health status. ${ }^{29}$ This putative right derives from respect for autonomy: the right to determine what we do and do not wish to know about our health. Directly providing a letter to relatives could be construed as a more significant breach of this right when compared with information being passed on by the proband.

However, if the options for preventing the onset of disease are significant (as they are for $\mathrm{FH}$ ), there is little reason to suppose that relatives would not be interested in this kind of information. Our biology does not stop: the risk of developing $\mathrm{CHD}$ as a consequence of $\mathrm{FH}$ will still be present, even if relatives live in ignorance. Contrary to other conditions where the possibility of medically relevant interventions after presymptomatic testing is nonexistent or minimal (such as Huntington's Disease), there appears to be an ethical imperative to provide a choice. This is not to suggest that people should have unsolicited definitive risk information provided to them, but the right to remain in ignorance may not extend to the knowledge that a preventable genetic condition such as $\mathrm{FH}$ is present within one's family. This contention is further supported by public health models, where individualistic ethical principles are subordinated in favour of acting beneficently towards the community as a whole. ${ }^{30}$

This suggests, therefore, that relatives' autonomy will be best respected by their knowing that a risk is present and receiving assistance in coming to a decision about whether or not to undergo testing. The right 'not to know' about health status therefore has little impact upon the ethical standing of alternative methods of contact.

\section{Actual harm to relatives}

In debates over genetic screening and testing, the potential for actual harm is often discussed. A person may be subject to discrimination or stigmatisation as a result of receiving genetic information. For example, one's ability to obtain life insurance at normal premium levels can be affected by a family history of disease, although in practice, the health questionnaire or medical examination required would usually identify the family history of high cholesterol. We have recently reported that most companies offer insurance to untreated FH patients at a higher premium, which is appropriate for a condition with a reduced life expectancy, but at a lower premium if the condition is well treated. $^{31}$ The issue of a DNA based test result is not currently relevant since there is a UK moratorium (until late 2005) on using such genetic test results for life insurance policies of less than $£ 500000$.

Therefore cascade screening using direct contact instead of family contact will not further raise the potential for discrimination, which is minimal in any case. Relatives will receive a generalised letter warning of an increased risk of the symptoms of $\mathrm{FH}$, taking into account their family history. The effect of this letter will not be vastly different to that which would occur where a family member passes on the information. In both cases, a person who currently knows that he or she is at somewhat increased risk (for example, having a parent who died of a heart attack) will not be in a substantially different position afterwards. Many relatives are already likely to realise that high cholesterol or CHD runs in their family, and this will be taken into account by insurers regardless of the information received via cascade screening.

Direct contact will therefore not deny relatives the chance to make arrangements about life insurance. Risk status is only likely to change once an actual test result is received.

\section{A detrimental impact on family dynamics}

Relatives may feel aggrieved if a proband does not discuss his or her condition with them prior to an approach by the cascade project team. Introducing knowledge of a heritable condition can draw out feelings of guilt and blame, particularly if existing relationships are strained. The 
nuances of intrafamilial relationships must be taken into account when direct contact is being considered. Therefore, where direct contact is to be introduced, discussions should be held with the proband to determine the contextual features of his or her family's structure, and potential difficulties arising from direct contact. If a proband reports any potential difficulties, alternative methods of approach should be used. Ideally, the clinical service should work with the proband to attain a tailored approach to family contact. ${ }^{32}$

\section{Breach of confidentiality}

Clinical care in genetic medicine is such that, in the majority of clinical consultations, information is collected about family members beyond the proband or consultand. While this is generally considered as necessary for the provision of good clinical care, the recording of relatives' contact details, in addition to their name, could be seen as a breach of confidentiality. The confidentiality of the proband's health information may also be at risk.

The issue of protecting relatives' confidentiality will be difficult to overcome without introducing significant limitations to the process of direct contact. Although the proband could be asked to approach relatives to determine whether they would like to be contacted by the clinic, introducing this step will mean that many relatives will be lost to contact if the proband does not report back. We propose a compromise: relatives' names and addresses should not be recorded in the cascade screening register until they have positively responded to contact.

\section{The potential for undue influence}

Using a clinical pretext when contacting relatives may cause them to perceive pressure to participate in testing they may not have chosen otherwise. Van Maarle et $a l^{21}$ reported that relatives did perceive such pressure: $20 \%$ of participants felt as if the circumstances they were in more or less forced them to participate, and 63\% agreed with the statement that they participated out of solidarity with their families.

However, just as the clinical veil is potentially problematic, so is family-initiated contact. A proband enrolled in cascade screening may engage in a 'crusade' to convince relatives to undergo testing, which could place them under more pressure than clinical contact ever would.

The potential for undue influence should not, however, go unrecognised. Whilst active promotion of cascade screening is important to the programme's success, clinical teams should ensure that this is not taken beyond reasonable expectations for professionals in this area. Therefore, any materials sent directly to relatives should emphasise the voluntary nature of testing, and stipulate that nonparticipation will not prejudice the proband's health care in any way.

\section{Advantages of direct contact}

The efficiency of cascade testing programmes

How relatives are offered screening is likely to be a major determinant of uptake rates. Under direct contact, the number of relatives presenting for screening is likely to be significantly higher than if recruitment were left to probands. The overall cost-effectiveness of a cascade screening program is likely to be higher with direct contact, and a greater number of people will receive potentially life-saving health information and advice. Although no studies have been undertaken to directly compare these two methods of family tracing, other investigations lend significant weight. For example, Sermijn et $a^{33}$ recently reported that, in the context of Brca1/2 clinical testing, the 'transfer of information from probands to their relatives is highly defective' and that a process of systematically informing relatives of mutation carriers is warranted. This process would be provided for if direct contact were adopted.

This efficiency increase should, however, be balanced with the above ethical concerns and also broader concerns raised by the use of public health genetic models over individual clinical care. ${ }^{30}$ Concerns about privacy, stigmatisation and psychological harm should not be over-ridden to optimise a cascade screening programme. Therefore, efficiency should be a relevant factor in determining methods of relative contact, but it should not be the only consideration. Compromises may be necessary, such as providing a general leaflet to probands for distribution prior to relative contact.

\section{Increased accuracy of information}

Many relatives will already know of the presence of a condition like FH within their family, because one or several relatives will have had a heart attack, and this basic understanding may result in an increase in relatives' desire to find out more. ${ }^{28}$ However, if probands were to contact relatives, the quality of the information they receive could deteriorate. Patients do not have perfect recall of information provided to them during counselling, ${ }^{34}$ and there are instances of incorrect information having being passed to family members. ${ }^{27}$ Even if written information is provided to the proband, they may fail to provide it to their relatives, instead giving their own account of the nature of the condition. By contrast, if direct contact methods were employed, the clinic could ensure that all relatives received the same high-quality information.

Again, however, accuracy alone should not be an overriding consideration in justifying direct contact. Indeed, employing good clinical follow-up with probands could ensure that written information is passed on. However, if information is clearly not being communicated, the clinic could ask the proband whether it would be better for them to contact relatives directly. 


\section{Preventing harm to the proband}

Direct contact has a potential advantage of actually preventing harm to probands. It can be very difficult to discuss the risk of a heritable condition with family members. Probands may still be coming to terms with their own diagnosis, and may not feel ready for discussions with relatives. Direct contact can remove this burden by 'professionalising' the contact.

\section{An ethical 'duty to warn'?}

For a variety of reasons, genetic risk information is not always disseminated throughout families. Families may not get along, or there be other complicating factors, such as a suspicion of nonpaternity. Therefore, some probands will refuse to mediate any access to relatives. This is likely to be an uncommon occurrence and will often be resolvable through continuing discussion between the proband and the cascade testing team. ${ }^{26}$ Still, failures to provide relatives' details have been described. ${ }^{20}$ This gives rise to a dilemma: if a proband refuses contact, should his or her confidentiality be breached in order to promote relatives' autonomous decision-making?

Much has been written about this ethical 'duty to warn.' For example, the Human Genetics Commission has concluded: ${ }^{35}$

... disclosure of sensitive personal genetic information for the benefit of family members in certain circumstances may occasionally be justified. This would arise where a patient refuses to consent to such disclosure and the benefit of disclosure substantially outweighs the patient's claim to confidentiality (at [3.68]).

Other justifications for breaching confidentiality include the 'right to know' one's genetic risks, the facilitation of relatives' future decision-making, and the emerging argument that genetic information is 'familial information', not 'individual information'. ${ }^{36}$

For FH and other conditions where there is a proven intervention to prevent the onset of disease, the justification for breaching confidentiality in cascade testing may be stronger. However, we also recognise that with $75 \%$ of probands still to be identified, a failure to warn of genetic risk could be overcome via other means, such as public education. The contact tracing protocol should foresee this issue and consider various alternative courses for action. Ultimately, any breach of confidentiality should only be considered when certain criteria are met, summarised in Table 2.

\section{Conclusion}

\section{Recommendation and practical strategy}

It may not be appropriate to straightforwardly and inflexibly adopt the direct contact method of family
Table 2 Criteria to be met when breaching confidentiality is contemplated ${ }^{37}$

(1) Identifiable relatives are at significant, foreseeable, quantifiable risk of a serious condition

(2) Earlier intervention could reduce or alleviate serious harm

(3) Harm from the failure to disclose must outweigh the harm caused by disclosure

(4) Reasonable efforts to elicit disclosure fail after 2-3 meetings with proband

(5) Alternative means of contacting the relative have been exhausted

(6) Proband is briefed about the intention to breach confidentiality

tracing for FH. This approach should not be taken at the expense of involving the proband, who should be given an adequate opportunity to communicate with his or her family members prior to contact being initiated by the cascade screening programme.

We therefore propose that, rather than implementing direct contact tracing as soon as the proband has given permission for this to take place, it is preferable to do this only after initial family contact has been established by the proband, if they indicate their wish to do so. This renders the cascade screening programme as a 'second line' of contact but the main source of information, counselling and advice. This method of contact is flexible enough to allow families time for digestion and communication of information, yet will facilitate a greater rate of case identification. Probands will feel more empowered, yet will not have responsibility for following up all of their relatives. If a proband fails to respond to the clinic, a follow-up phone call can initiate direct contact.

In developing a protocol for contacting relatives, several potential problems will need to be taken into consideration. The following recommendations should therefore be incorporated into protocol design:

1. A nurse or doctor who has appropriate training should discuss the prospect of contact tracing with probands.

2. Probands should be provided with information to pass on to relatives before clinic contact. If no responses are received, contact the proband again to ask if clinicinitiated contact would be preferred.

3. Direct contact with relatives should use general language to avoid reactions of alarm and concern. The voluntary nature of testing should be emphasised.

4. Contact tracing should be tailored to each family by discussing aspects such as intrafamilial relationships and cultural factors with the proband. If a proband reports any potential difficulties, alternative methods of approach should be used. Contacting family members could be managed using the 'Contextual Assessment Approach' of Arar et al. ${ }^{32}$ 
5. Do not record the names or addresses of relatives in the cascade screening register until they have positively responded to contact.

6. Have detailed procedures to determine what to do if a proband refuses relative contact.

A further ideal for the successful implementation of any contact tracing program is to appropriately and effectively monitor the impact of the tracing method in place, and to ensure a variety of ethnic groups are included in any studies which monitor quality of life and health outcomes following screening for genetic conditions.

\section{Acknowledgements}

We thank Richard Ashcroft, Cyril Chapman, Gaye Hadfield, Alastair Kent, Graeme Laurie and the paper's anonymous referees for valuable comments and assistance with an earlier draft of this paper. SEH is supported by The British Heart Foundation and AJN by the IDEAS Genetics Knowledge Park; a grant from the UK Departments of Health and of Trade and Industry.

\section{References}

1 Goldstein JL, Brown MS: Familial hypercholesterolaemia; in Scriver CR, Beudet AL, Sly WS et al (eds): The Metabolic Basis of Inherited Disease. New York: McGraw-Hill, 2000, pp $1215-1245$.

2 Stone NJ, Levy RI, Fredrickson DS, Verter J: Coronary artery disease in 116 kindred with familial type II hyperproteinemia. Circulation 1974; 49: 476-488.

3 Slack J: Risks of ischaemic heart-disease in familial hyperlipoproteinaemic states. Lancet 1969; 27: 1380-1382.

4 Neil HA, Hammond T, Huxley R, Matthews DR, Humphries SE: Extent of underdiagnosis of familial hypercholesterolaemia in routine practice: prospective registry study. BMJ 2000; 321: 148.

5 Scientific Steering Committee on behalf of the Simon Broome Register Group: Mortality in treated heterozygous familial hypercholesterolaemia: implications for clinical management. Atherosclerosis 1999; 142: 105-112.

6 Thompson GR, Maher VM, Matthews S et al: Familial hypercholesterolaemia regression study: a randomised trial of lowdensity-lipoprotein apheresis. Lancet 1995; 345: 811-816.

7 Heath KE, Humphries SE, Middleton-Price H, Boxer M: A molecular genetic service for diagnosing individuals with familial hypercholesterolaemia (FH) in the United Kingdom. Eur J Hum Genet 2001; 9: 244-252.

8 Marks D, Wonderling D, Thorogood M, Lambert H, Humphries SE, Neil HA: A cost-effectiveness analysis of different approaches of screening for familial hypercholesterolaemia. BMJ 2002; 324: 1303.

9 Leren TP: Cascade genetic screening for familial hypercholesterolaemia (review). Clin Genet 2004; 66: 483-487.

10 Umans-Eckenhausen MA, Defesche JC, Sijbrands EJ, Scheerder RL, Kastelein JJ: Review of first 5 years of screening for familial hypercholesterolaemia in the Netherlands. Lancet 2001; 357: $165-168$

11 van Maarle MC, Stouthard ME, Bonsel GJ: Quality of life in a family based genetic cascade screening programme for familial hypercholesterolaemia: a longitudinal study among participants (letter). J Med Genet 2003; 40: e3.

12 Secretary of State for Health: Our Inheritance, Our Future: Realising the Potential of Genetics in the NHS 2003, http://www.dh.gov.uk/
assetRoot/04/01/92/39/04019239.pdf $\quad(1$ June 2004) at [3.10]-[3.12].

13 Godard B, Raeburn S, Pembrey M, Bobrow M, Farndon P, Ayme S: Genetic information and testing in insurance and employment: technical, social and ethical issues. Eur J Hum Genet 2003; 11: S123-S142.

14 Andersen LK, Jensen HK, Juul S, Faergeman O: Patients' attitudes toward detection of heterozygous familial hypercholesterolemia. Arch Intern Med 1997; 157: 553-560.

15 Marteau T, Senior V, Humphries S et al: Psychological impact of genetic testing for familial hypercholesterolaemia within a previously aware population: a randomized controlled trial. Am J Med Genet 2004; 128A: 285-293.

16 Chandros Hull S, Glanz K, Steffen A, Wilfond BS: Recruitment approaches for family studies: attitudes of index patients and their relatives. IRB: Ethics Hum Res 2004; 26: 12-18.

17 Worral B, Chen D, Meschia J: Ethical and methodological issues in pedigree stroke research. Stroke 2001; 32: 12421249.

18 Tonstad S, Vollebaek LE, Ose L: Screening for familial hypercholesterolaemia in relatives (letter). Lancet 1995; 346: 1438.

19 Laurie G: Obligations arising from genetic information negligence and the protection of familial interests. Child Family Law Quart 1999; 11: 109-124.

20 Bhatnagar D, Morgan J, Siddiq S, Mackness MI, Miller JP, Durrington PN: Outcome of case finding among relatives of patients with known heterozygous familial hypercholesterolaemia. BMJ 2000; 321: 1497-1500.

21 van Maarle MC, Stouthard ME, Marang-van de Mheen PJ, Klazinga NS, Bonsel GJ: How disturbing is it to be approached for a genetic cascade screening programme for familial hypercholesterolaemia? Psychological impact and screenees' views. Community Genet 2002; 4: 244-252.

22 Ose L, Vollebaek LE, Tonstad S: Attitude to genetic screening for familial hypercholesterolemia [Norwegian]. Tidsskr Nor Laegeforen 1998; 118: $1578-1581$

23 Morris JK, Law MR, Wald NJ: Is cascade testing a sensible method of screening a population for autosomal recessive disorders? Am J Med Genet 2004; 128A: 271-275.

24 Wilcke JT, Seersholm N, Kok-Jensen A, Dirksen A: Transmitting genetic risk information in families: attitudes about disclosing the identity of relatives. Am J Hum Genet 1999; 65: 902-909.

25 Wilcke JT, Seersholm N, Kok-Jensen A, Dirksen A: Attitudes toward an unsolicited approach in relation to status of genetic disease: exemplified by alpha(1)-antitrypsin deficiency. Am J Med Genet 2000; 94: 207-213.

26 Wright C, Kerzin-Storrar L, Williamson PR et al: Comparison of genetic services with and without genetic registers: knowledge, adjustment, and attitudes about genetic counselling among probands referred to three genetic clinics. J Med Genet 2002; 39: e84.

27 Kerzin-Storrar L, Wright C, Williamson PR et al: Comparison of genetic services with and without genetic registers: access and attitudes to genetic counselling services among relatives of genetic clinic patients. J Med Genet 2002; 39: e85.

28 Super M, Schwarz MJ, Malone G, Roberts T, Haworth A, Dermody G: Active cascade testing for carriers of cystic fibrosis gene. $B M$ ) 1994; 308: 1462-1467.

29 Chadwick R, Levitt M, Shickle D (eds): The Right to Know and the Right Not to Know. Aldershot, Avebury, 1997.

30 Hodge JG: Ethical issues concerning genetic testing and screening in public health. Am J Med Genet 2004; 125C: 66-70.

31 Neil HA, Hammond T, Mant D, Humphries SE: Effect of statin treatment for familial hypercholesterolaemia on life assurance: results of consecutive surveys in 1990 and 2002. BMJ 2004; 328: 500-501.

32 Arar NH, Plaetke R, Arar MY, Kasinath BS, Abboud HE: Incorporating the contextual assessment approach to 
regimens used in genetic family studies. Genet Med 2002; 4: 451-463.

33 Sermijn E, Goelen G, Teugels E et al: The impact of proband mediated information dissemination in families with a BRCA1/2 gene mutation (letter). J Med Genet 2004; 41: e23.

34 Gordon C, Walpole I, Zubrick SR, Bower C: Population screening for cystic fibrosis: knowledge and emotional consequences 18 months later. Am J Med Genet 2003; 120A: 199-208.
35 Human Genetics Commission: Inside information: balancing interests in the use of personal genetic data, 2002, http:// www.hgc.gov.uk/insideinformation/ (15 April 2004).

36 Parker M, Lucassen A: Genetic information: a joint account? BMJ 2004; 329: $165-167$.

37 ASHG Social Issues Subcommittee on Familial Disclosure: Professional disclosure of familial genetic information. Am J Hum Genet $1998 ; 474-483$. 